\title{
A novel method for detection of HBVcccDNA in hepatocytes using rolling circle amplification combined with in situ PCR
}

\author{
Yanwei Zhong ${ }^{1{ }^{*}}$, Shuangye $\mathrm{Hu}^{1+}$, Chen $\mathrm{Xu}^{1+}$, Yulai Zhao ${ }^{1}$, Dongping $\mathrm{Xu}^{1}$, Yanqing Zhao ${ }^{1}$, Jingmin Zhao ${ }^{1}$, \\ Zhibin $\mathrm{Li}^{1}$, Xiuchang Zhang ${ }^{2}$, Hongfei Zhang ${ }^{1 *+}$ and Jin $\mathrm{Li}^{1{ }^{*+}}$
}

\begin{abstract}
Background: Intrahepatic hepatitis B virus (HBV) covalently closed circular DNA (cccDNA) is the original template for HBV replication. The persistence of cccDNA is responsible for the recurrence of HBV infection. The detection of cccDNA can help the development of new antiviral drugs against HBV replication links, and reduce the resistance and recurrence as well as to discover extrahepatic HBV infection. In situ polymerase chain reaction (IS-PCR) can be used to determine the distribution and localization of cccDNA in liver tissues, but it is hampered by its low sensitivity and specificity. We developed a novel method to detect HBV cccDNA using rolling circle amplification (RCA) combined with IS-PCR.
\end{abstract}

Methods: Biopsy liver tissues were obtained from 26 patients with HBV infection, including 10 chronic hepatitis B $(\mathrm{CHB}), 6$ liver cirrhosis $(\mathrm{LC})$ and 10 hepatocellular carcinoma $(\mathrm{HCC})$ patients. Four pairs of primers were designed to mediating RCA for the first round amplification of HBV cccDNA specifically. The liver tissue sections from patients were treated by plasmid-safe ATP-dependent DNase (PSAD) prior to RCA. After RCA, HBV ccCDNA was further amplified by a pair of selective primers labeled digoxigenin that target the gap region between the two direct repeat regions (DR1 and DR2) of the virus via IS-PCR.

Results: HBVcccDNA was expressed and located in hepatocyte nucleus in 19 patients (73.07\%). Compared with the IS-PCR, the introduction of RCA increase the limit of detection. RCA combined with IS-PCR yielded strong positive signals in HCC liver tissue in spite of low copy number cccDNA (2 copies of target sequence per cell), meanwhile, no positive signal was detected via negative control.

Conclusions: RCA combined with IS-PCR is an effective and practicable method which could detect the presence of low copy number of cccDNA sensitively and specifically, and reflect the relationship between cccDNA expression level and liver tissue pathological characteristics.

Keywords: Covalently closed circular DNA, Hepatitis B virus, In situ PCR, Rolling circle amplification

\section{Background}

Chronic hepatitis B virus (HBV) infection remains a serious health problem that currently affects over 350 million people in the world and 93 million people in China [1-3]. It is estimated that 500000 to 1000000 people die each year from HBV-related liver disease, such as

\footnotetext{
*Correspondence: zhongyanwei@126.com; zhanghongfei302@163.com; lijin302302@126.com

${ }^{\dagger}$ Equal contributors

'Institute of Infectious Diseases, Beijing 302 Hospital, Beijing, China Full list of author information is available at the end of the article
}

liver cirrhosis (LC), hepatic decompensation, and hepatocellular carcinoma (HCC) [4]. Treatment of chronic hepatitis $\mathrm{B}(\mathrm{CHB})$ is aimed at suppressing viral replication to the lowest possible level, and thereby to halt the progression of liver disease and prevent the onset of complications [5]. However, it has always been hampered by the high relapse rate after discontinuation of the treatment. One crucial step within the HBV life cycle is the formation of covalently closed circular DNA (cccDNA), which serves as original template for viral replication with approximately 5-50 cccDNA molecules 
per infected hepatocyte [6]. Intrahepatic HBV cccDNA is responsible for the persistence of the disease in hepatocytes and it has been a key indicator to evaluate antiHBV therapeutic efficacy $[7,8]$. In addition, the HBV cccDNA level is considered to be valuable for studying HBV recurrence after liver transplantation and extrahepatic $\mathrm{HBV}$ infection $[9,10]$.

The development of highly selective real-time polymerase chain reaction (PCR) assays has provided sensitive tools to investigate the replicate activity and the effectiveness of antiviral therapy in infected patients by detection and quantification of the cccDNA in human liver biopsies [11-13]. However, the problem of nonspecific amplification of relaxed circular DNA (rcDNA) is a major obstacle in the development of an accurate cccDNA quantification assay. In a previous study, we improved and developed a quantification by introducing rolling circle amplification (RCA) steps combined with plasmid-safe ATP-dependent DNase (PSAD) digestion and real-time PCR, which offered better resolution [14]. However, these quantitative analysis methods could not reveal the distribution and localization of HBV cccDNA in liver tissues and further analyze the relationship between cccDNA and pathological characteristics.

Therefore, we developed a new sensitive and specific method for the locating detection of HBVcccDNA in sections from formalin fixed paraffin-embedded (FFPE) liver tissues by using RCA combined with in situ polymerase chain reaction (IS-PCR).

\section{Methods}

\section{Ethics statement}

This study was approved by the ethics committee of Beijing 302 Hospital. In this study, all samples were the residuary tissues of pathological examination, limited to in vitro studies, and didn't have any contact and harm to patients, the institutional review board has waived the need for written informed consent from the participants.

\section{Study subjects}

FFPE liver biopsy tissues (from the residuary tissues of pathological examination) were obtained from $26 \mathrm{HBV}$ infected patients (21 male, 5 female; median age 39.73 years), hospitalized in Beijing 302 Hospital during a period from July 2011 - July 2012. According to the imaging and histological examination of liver, the patients were grouped into $10 \mathrm{CHB}$ patients, $6 \mathrm{LC}$ patients and $10 \mathrm{HCC}$ patients. The characteristics of the patients are shown in Table 1 . None of the patients received anti-HBV agents or steroids within six months prior to sampling. Concurrence of HCV, HDV, HIV infection, autoimmune liver disease and alcoholic liver disease was excluded for all enrolled individuals. FFPE liver biopsy tissues from four subjects without HBV infection (including two patients with $\mathrm{HCV}$, one liver transplant from a healthy donor) and one of mice which transgenic complete $\mathrm{HBV}$ genomes) were collected as negative control.

\section{Serological markers and quantification of HBV DNA and cccDNA}

Serum ALT, HBeAg/anti-HBe and other serological markers were routinely measured or detected in the Central Clinical Laboratory of the Beijing 302 Hospital. Serum HBV DNA level was determined by real -time quantitative PCR kit (Fosun Pharmaceutical Co., Ltd., Shanghai, China) with a lower detection limit of $100 \mathrm{IU} / \mathrm{ml}(\approx 500$ copies/ml). Quantification of intrahepatic HBV cccDNA using rolling circle amplification in combination with real-time PCR according to the literature [14]. Intrahepatic HBV cccDNA levels were normalized by the amount of human genomic (hg)-betaactin in the samples. Cell numbers were calculated based on an estimation of $6.667 \mathrm{pg} / \mathrm{hgDNA}$ per cell.

\section{Sample preparation}

The liver tissue samples were fixed in $10 \%$ buffered formalin ( $\mathrm{pH}$ 7.4) for $24 \mathrm{hrs,}$ embedded in paraffin, cut into $5 \mu \mathrm{m}$ sections, and mounted on $0.05 \%$ poly-L-Lysine glass slides, followed by incubation at $60^{\circ} \mathrm{C}$ for $2 \mathrm{hrs}$. Tissue sections $(5 \mu \mathrm{m})$ were first stained with hematoxylin and eosin (HE) and studied to confirm the adequacy of the biopsy.

\section{Deparaffinization and digestion}

The sections were deparaffinized with two pre-warmed $x y$ lene washes followed by $95 \%, 75 \%$, and $50 \%$ ethanol rinses. The sample slides were dried at room temperature after washing in distilled water. After deparaffinizing by the normal method, the tissue sections on the glass slides were digested with proteinase $\mathrm{K}$ (Boster Biotech, Wuhan, China) $50 \mu \mathrm{g} / \mathrm{ml}$ at $37^{\circ} \mathrm{C}$ for $10 \mathrm{~min}$ in a humidified chamber and then the sections were rinsed with phosphate-buffer saline (PBS). PSAD (Epicentre, Madison, Wisconsin, USA) was used to digest $\mathrm{HBV}$ rcDNA, replicate double-stranded DNA (dsDNA) and single-stranded DNA (ssDNA). The reaction mixture contained 3U PSAD, $1.0 \mathrm{mmol} / \mathrm{l}$ ATP and $1 \mu \mathrm{l} 10 \times$ reaction buffers, with doubly distilled water $\left(\mathrm{ddH}_{2} \mathrm{O}\right)$ to final volume of $15.5 \mu \mathrm{l}$. The digestion was carried out at $37^{\circ} \mathrm{C}$ for $30 \mathrm{~min}$ and inactivated at $70^{\circ} \mathrm{C}$ for $30 \mathrm{~min}$. Endogenous alkaline phosphatase (AP) in the liver tissues was removed byusing $20 \%$ acetic acid (in order to increase the permeability of cell membrane) for $10 \mathrm{~min}$ at room temperature. Subsequently, the sections were fixed in $4 \%$ formaldehydum polymerisatum, rinsed with distilled water, dehydrated by $75 \%$ ethanol, $95 \%$ ethanol and 100\% ethanol, and air dried. 
Table 1 Patient profiles and results of the present study

\begin{tabular}{|c|c|c|c|c|c|c|c|c|}
\hline Patient No. & Age (year) & Gender & Serum ALT (IU/L) & $\mathrm{HBs} \mathrm{Ag}$ & $\mathrm{HBe} \mathrm{Ag}$ & Serum HBV DNA (IU/mL) & PSAD + RCA + IS-PCR detect HBVcccDNA & Note \\
\hline \multicolumn{9}{|l|}{$\mathrm{CHB}$} \\
\hline 1 & $0-10$ & M & 89 & + & + & $1.33 \times 10^{7}$ & + & \multirow[t]{10}{*}{ Figure 2} \\
\hline 2 & $21-30$ & M & 68 & + & + & $1.46 \times 10^{2}$ & + & \\
\hline 3 & $21-30$ & M & 22 & + & + & $3.595 \times 10^{2}$ & + & \\
\hline 4 & $21-30$ & M & 197 & + & - & $7.51 \times 10^{4}$ & + & \\
\hline 5 & $11-20$ & M & 21 & + & + & $3.54 \times 10^{8}$ & + & \\
\hline 6 & $11-20$ & M & 13 & + & + & $1.51 \times 10^{3}$ & - & \\
\hline 7 & $50-60$ & M & 45 & + & - & $1.2 \times 10^{5}$ & - & \\
\hline 8 & $50-60$ & M & 263 & + & + & $2.73 \times 10^{5}$ & + & \\
\hline 9 & $20-30$ & $\mathrm{~F}$ & 54 & + & - & $3.03 \times 10^{4}$ & - & \\
\hline 10 & $20-30$ & $\mathrm{~F}$ & 381 & + & + & $4.75 \times 10^{7}$ & + & \\
\hline \multicolumn{9}{|l|}{ LC } \\
\hline 1 & $40-50$ & M & 20 & + & - & $5.13 \times 10^{7}$ & + & \multirow[t]{6}{*}{ Figure 3} \\
\hline 2 & $40-50$ & M & 58 & + & - & $1.509 \times 10^{4}$ & + & \\
\hline 3 & $40-50$ & M & 33 & + & - & $1.17 \times 10^{3}$ & + & \\
\hline 4 & $50-60$ & M & 25 & + & + & $4.542 \times 10^{3}$ & + & \\
\hline 5 & $50-60$ & M & 136 & + & - & $3.08 \times 10^{2}$ & - & \\
\hline 6 & $40-50$ & $\mathrm{~F}$ & 44 & + & + & U.D. & - & \\
\hline \multicolumn{9}{|l|}{$\mathrm{HCC}$} \\
\hline 1 & $30-40$ & M & 55 & + & - & U.D. & + & \multirow[t]{10}{*}{ Figure 4} \\
\hline 2 & $40-50$ & M & 47 & + & - & U.D. & + & \\
\hline 3 & $40-50$ & M & 12 & + & - & $2.829 \times 10^{2}$ & - & \\
\hline 4 & $40-50$ & M & 44 & + & - & $2.446 \times 10^{6}$ & + & \\
\hline 5 & $50-60$ & F & 25 & + & + & $2.182 \times 10^{4}$ & + & \\
\hline 6 & $50-60$ & M & 14 & + & - & $1.11 \times 10^{3}$ & + & \\
\hline 7 & $60-70$ & M & 88 & + & + & $1.79 \times 10^{3}$ & + & \\
\hline 8 & $60-70$ & M & 17 & - & - & U.D. & + & \\
\hline 9 & $40-50$ & $\mathrm{~F}$ & 35 & + & - & $4.464 \times 10^{3}$ & - & \\
\hline 10 & $30-40$ & M & 206 & + & - & $4.44 \times 10$ & + & \\
\hline
\end{tabular}

M, male; F, female; U.D., undetected; HBV, hepatitis B virus; ALT, alanine aminotransferase; HBsAg, hepatitis B surface antigen; HBeAg, hepatitis B e antigen; PSAD, plasmid-safe ATP-dependent DNase; RCA, rolling circle amplification; IS-PCR, situ polymerase chain reaction; CHB, chronic hepatitis B; LC, liver cirrhosis; HCC, hepatocellular carcinoma. 


\section{RCA treatment}

Four pairs of primers were designed for mediating RCA for the first amplification round of HBV cccDNA specifically (Table 2). In order to increase the efficiency of amplification, RCA was divided into two steps: First-step, $14 \mu \mathrm{l}$ primer combining reaction mixture containing primers at a operative solutionconcentration of $0.5 \mu \mathrm{mol} / \mathrm{l}$ each , $2 \mu \mathrm{l}$ reaction buffer and $11 \mu \mathrm{lddH_{2 }} \mathrm{O}$ were loaded onto the tissue sections on glass slides and sealed with rubber cement, followed by heating at $95^{\circ} \mathrm{C}$ for $6 \mathrm{~min}$, and then placed on ice for $15 \mathrm{~min}$. Second-step the RCA amplification was as follows: $23 \mu \mathrm{l}$ of reaction mixture was added to tissue slides containing primers at a operative solution concentration of $0.5 \mu \mathrm{mol} / \mathrm{l}$ each, $10 \mathrm{mg} / \mathrm{ml}$ bovine serum albumin (BSA), $0.32 \mathrm{mmol} / \mathrm{l}$ of dNTP, $20 \mathrm{U}$ of the Phi29 DNA polymerase (New England Biolabs, Worcester, MA), and $2 \mu$ reaction buffer. Reaction was carried out overnight for $16 \mathrm{hrs}$ at $30^{\circ} \mathrm{C}$. Then Phi29 DNA polymerase was inactivated at $70^{\circ} \mathrm{C}$ for $10 \mathrm{~min}$. Subsequently, the sections were fixed in $4 \%$ formaldehydum polymerisatum, rinsed with distilled water, dehydrated in a graded series of alcohol and air dried.

\section{IS-PCR and immunohistochemical staining for detecting HBV cccDNA}

HBV cccDNA was further amplified with IS-PCR mediated by a pair of cccDNA-selective primers labeled with digoxigenin at 5 '-terminal, that targets the gap region between the two direct repeat regions (DR1 and DR2) of the viral genome (Table 2) [14]. $23.5 \mu \mathrm{l}$ reaction solution containing a operative solutionconcentration of $0.32 \mathrm{mmol} / \mathrm{L}$ dNTP, $10 \mathrm{mg} / \mathrm{ml} \mathrm{BSA,} 3.5 \mu \mathrm{mol} / \mathrm{l} \mathrm{MgCl}_{2}, 5 \mu \mathrm{l}$ of Taq polymerase PCR buffer, $5 \mu \mathrm{l}$ of $\mathrm{ddH}_{2} \mathrm{O}, 0.2 \mu \mathrm{mol} / \mathrm{l}$ of selective primers, and $10 \mathrm{U}$ Taq polymerase (TaKaRa Biotechnology, Dalian, China) was added to the tissue slides and sealed with rubber cement. The slides were encapsulated with silver paper and placed in the thermal cycle system (ThermoPX2, USA) at $95^{\circ} \mathrm{C}$ for $3 \mathrm{~min}$ followed by $30 \mathrm{cy}$ cles of $95^{\circ} \mathrm{C}$ for $1 \mathrm{~min}, 55^{\circ} \mathrm{C}$ for $90 \mathrm{~s}, 72^{\circ} \mathrm{C}$ for $90 \mathrm{~s}$ and a final extension at $72^{\circ} \mathrm{C}$ for $10 \mathrm{~min}$. Immediately after the PCR, the slides were fixed in $4 \%$ paraformaldehyde for $10 \mathrm{~min}$, washed in Tris-HCl buffer saline (TBS) for $3 \mathrm{~min}$, rinsed with distilled water for $3 \mathrm{~min}$, dehydrated in a graded series of alcohol and air dried.

After IS-PCR, sample slides were washed with $0.1 \%$ Triton $\mathrm{X}-100$ in Tris-HCl buffer saline (TBS-T) for $10 \mathrm{~min}$ and TBS for $3 \mathrm{~min}$ at room temperature. After incubated in blocking reagent $3 \% \mathrm{BSA}$ at $37^{\circ} \mathrm{C}$ temperature for $10 \mathrm{~min}$, the slides were covered with $100 \mu \mathrm{l}$ Alkaline phosphatase, conjugated Monoclonal Anti-Digoxin (SIGMA, Saint Louis, Missouri, USA) and 1 than 30 dilution with TBS at $37^{\circ} \mathrm{C}$ for $120 \mathrm{~min}$. After this reaction, the slides were washed twice ( $3 \mathrm{~min}$ each) with TBS. The slides were incubated in $30 \mu \mathrm{l}$ dye solution $(338 \mu \mathrm{g} / \mathrm{ml}$ nitroblue tetrazolium chloride NBT, $175 \mu \mathrm{g} / \mathrm{ml}$ 5-bromo-4-chloro-3indolyl-phosphate 4-toluidine salt $\mathrm{BCIP}$ ) at $37^{\circ} \mathrm{C}$ in the dark. After sufficient color development, they were washed with de-ionized water for three times and then nuclear fast red re-stained. Finally, the slides were sealed by using neutral balsam for microscopic examination.

\section{Evaluation of sensitivity, repeatability and specificity of the assay}

To evaluate this method's sensitivity, we chose a liver tissue with low copy number ( 2 copies cccDNA per cell) from a HCC patient as template, which the quantification of intrahepatic HBV cccDNA according to our previous study [14]. The repeatability was evaluated by detecting the serial sections which were cut from same sample in inter-assay and intra-assay. Intra-assay reproducibility was assessed by repeating cccDNA detection of FFPE liver biopsy samples selected from three patients randomly from

Table 2 Oligonucleotide sequences of primers used in this study

\begin{tabular}{|c|c|c|c|}
\hline Name & Sequence $\left(5^{\prime} \rightarrow 3^{\prime}\right)$ & Nucleotide position & Polarity \\
\hline \multicolumn{4}{|c|}{ Primers for rolling circle amplification (RCA) } \\
\hline RCA1 & AATCCTCACAATA ${ }^{*} C^{*} \mathrm{C}$ & $226-240$ & Sense \\
\hline $\mathrm{RCA} 2$ & ACСТАТTСТССТС ${ }^{*} \mathrm{C}^{*} \mathrm{C}$ & $1744-1758$ & Antisense \\
\hline $\mathrm{RCA3}$ & CCTATGGGAGTGG ${ }^{*}{ }^{*} \mathrm{C}$ & $637-651$ & Sense \\
\hline RCA4 & CCTTTGTCCAAGG ${ }^{*}{ }^{*} \mathrm{C}$ & $2675-2689$ & Antisense \\
\hline RCA5 & ATGCAACTITITC ${ }^{*}{ }^{*} \mathrm{C}$ & $1814-1828$ & Sense \\
\hline RCA6 & CTAGCAGAGCTTG ${ }^{*}{ }^{*} T$ & $15-29$ & Antisense \\
\hline RCA7 & TAGAAGAAGAACT $^{*} \mathrm{C}^{*} \mathrm{C}$ & $2368-2382$ & Sense \\
\hline $\mathrm{RCA8}$ & GGGCCCACATATT ${ }^{*}{ }^{*} \mathrm{~T}$ & $2585-2599$ & Antisense \\
\hline \multicolumn{4}{|c|}{ Primers for in situ PCR (IS-PCR) } \\
\hline Pup58 & CCCCGTCTGTGCCTTCTC & $1547-1564$ & Sense \\
\hline Pdown84 & CAGCTTGGAGGCTTGAACAGT & 1859-1879 & Antisense \\
\hline
\end{tabular}

*Indicates primer phosphorothioate modifications so as to prevent degradation by nucleases. 
CHB、LC、HCC respectively for three times in a single run. Inter-assay variation was evaluated by detecting the three patients' samples mentioned above in three independent experiments. The specificity was assessed by examining FFPE liver biopsy tissue taken from the patients with $\mathrm{HCV}$, from healthy adults and from transgenic mice. In addition, FFPE liver biopsy tissue from the patient with HCC, which were amplified in situ omitting specific primer, labled primers, phi29 polymerase and Taq DNA polymerase respectively, instead of $\mathrm{ddH}_{2} \mathrm{O}$, were also examined for evaluation of the specificity of the assay.

\section{Methodological comparison}

Liver tissues from patients with $\mathrm{CHB}$ and HBV-related LC, HCC were detected using three different methods as follows:

1) Amplification of samples by IS-PCR (IS-PCR).

2) Treatment of samples with PSAD by IS-PCR (PSAD + IS-PCR).

3) Treatment of samples with PSAD followed by RCA prior to IS-PCR (PSAD + RCA + IS-PCR).

\section{Nucleotide sequence accession numbers}

The sequences accession numbers of the HBV genomes in GenBank are EU939666, FJ386583, FJ386632 and FG386652.

\section{Results}

Localization of HBVcccDNA

19 of $26(73.07 \%)$ samples from $\mathrm{HBV}$-infected patients including 7 of $10 \mathrm{CHB}, 4$ of $6 \mathrm{LC}$ and 8 of $10 \mathrm{HCC}$ were found positive for cccDNA by in situ amplification using PSAD + RCA + IS-PCR (Table 1). Liver cells with positive staining were scattered in tissues with clustering, and the signals compartment in the nuclear, staining blue or blueviolet. Interestingly, strong positive signals could be observed in the liver tissue from the patients with $\mathrm{HCC}$ despite of low copy number cccDNA. The detection threshold is 2 copies of target sequence per cell.

\section{Intra-assay and inter-assay variability experiments}

The positive expression intensity and distribution of replicate test were essentially consistent. Repeated experiments showed that this method shows good stability and reproducibility.

\section{Control study}

The specificity of PSAD + RCA + IS-PCR method was examined in a serious of control experiments. No positive signals were detected when the primers, phi29 polymerase or Taq DNA polymerase were omitted, neither in the liver specimens from the patients with $\mathrm{HCV}$, healthy adults and transgenic mice (Figure 1).

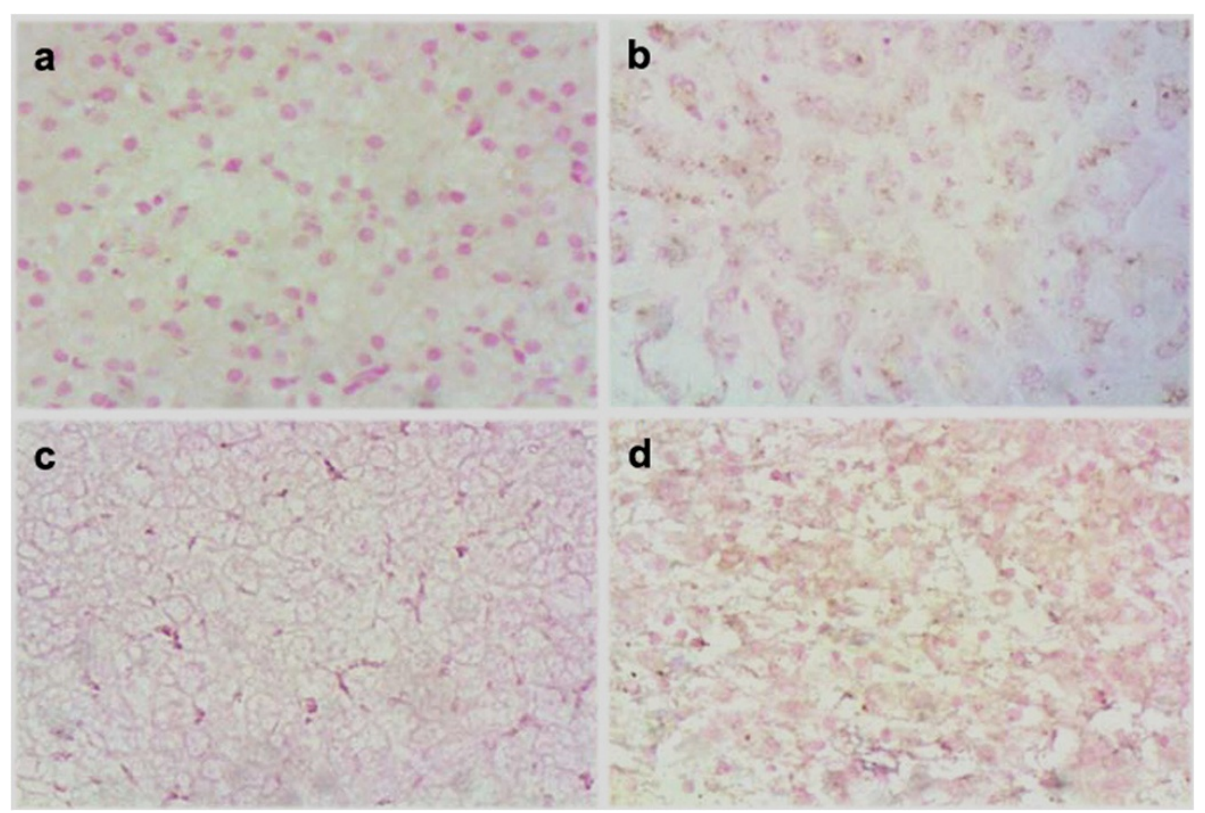

Figure 1 IS-PCR and immunohistochemical staining for detecting HBV cccDNA in FFPE liver biopsies. No positive signal was detected in liver tissue samples from HCV patient (a), healthy adults (b), transgenic mice (c) and HCC patients without specific primers (d) by PSAD + RCA + IS-PCR. Original Magnifications $\times 200$. 


\section{Methodological comparison}

Compared with IS-PCR methods, PSAD + RCA + IS-PCR increased the sensitivity and specificity of $\mathrm{HBV}$ cccDNA detection. HBVcccDNA were detected in the liver tissues from patients with CHB (Figure 2), LC (Figure 3) and HCC (Figure 4) by PSAD + RCA + IS-PCR, whereas no positive signal was detected in the consecutive tissue sections that were subjected to IS-PCR and PSAD + IS-PCR.

\section{Discussion}

HBV cccDNA plays a key role in the life cycle of the HBV and permits the persistence of infection. Studies have reported a development or improvement in the methodology to quantify viral cccDNA more specifically and sensitively [11,15-17]. Using this method, we developed a quantification of HBVcccDNA in FFPE liver tissue using RCA combined with real-time PCR and examined 130 samples from the patients with $\mathrm{CHB}$ in our previous studies [14]. In order to observe distribution and localization of HBV cccDNA in liver tissues and further analyze the relationship between cccDNA and pathological characteristics, we developed a highly specific and sensitive method to detect the HBV cccDNA in liver tissues via RCA combined with IS-PCR.

RCA is a novel isothermal DNA amplification method with an amplification mechanism quite different from conventional PCR. This method uses a specially designed circular probe (C-probe) in which the $3^{\prime}$ and $5^{\prime}$ ends are brought together in juxtaposition by hybridization to a target. The two ends are then covalently linked by a T4 DNA ligase in a target-dependent manner, producing a closed DNA circle. In the presence of an excess of primers (forward and reverse primers), a DNA polymerase extends the bound forward primer along the C-probe and displaces the downstream strand, generating a multimeric single-stranded DNA (ssDNA), analogous to the "rolling circle" replication of bacteriophages in vivo. This multimeric ssDNA then serves as a template for multiple reverse primers to hybridize, extend, and displace downstream
DNA, generating a large ramified (branching) DNA complex. This ramification process continues until all ssDNAs become double-stranded, resulting in an exponential amplification that distinguishes itself from the previously described nonexponential rolling circle amplification [18]. The major advantage of RCA is its efficiency and fidelity. It exhibits less amplification bias and greater yield, product length, and fidelity than conventional PCR [19]. In 2008, Margeridon et al. [20] first applied RCA for qualitatively probing HBV cccDNA. We also applied RCA to analyze drug resistant mutations of HBV cccDNA in patients with chronic hepatitis B [21]. RCA relies on the properties of the phi29 DNA polymerase that possesses a strong 3 exonuclease (proofreading) activity, is able to polymerize more than 70,000 nucleotides without detaching from the template, and that can displace previously elongated strands [20]. Phi29 DNA polymerase used in RCA can selectively amplify circular template molecule [22], it minimizes the impact of integrated HBV DNA and obviously improves the sensitivity and specificity of HBV cccDNA assay. In the present study, a more efficient amplification was operated by adding 4 pairs of RCA primers targeting multiple binding sites. Therefore, RCA were optimized to improve their sensitivity without impairing the specificity.

IS-PCR, which is the combination of PCR and ISH, was first described by Haase et al. in 1990 [23]. IS-PCR has the advantages of both PCR and ISH. It has been adapted to in situ amplification of viral genomes or their replicate intermediates in liver tissue sections [24,25] and can localize a single gene copy at the individual cell level [26-28]. But the sensitivity and specificity remain major challenges to the application.

In practice, IS-PCR is technically difficult, especially when using paraffin-embedded tissue sections, because there is no standard protocol for optimal detection. In fact, in this method the diffusion of the amplified products from the target cells is a major problem. The factors that influence diffusion include excessive protease digestion $[26,29]$ and the use of an excessive number of PCR

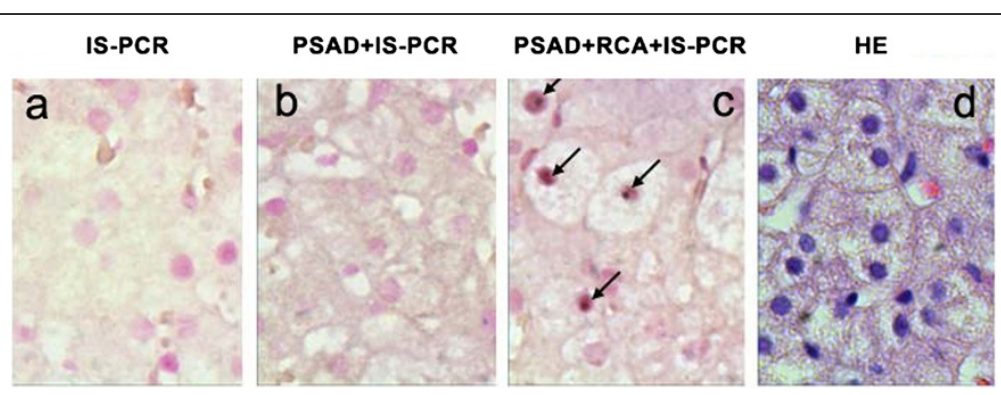

Figure 2 IS-PCR and immunohistochemical and HE staining for detecting HBV ccCDNA in FFPE liver biopsies of CHB patient.

HBV cccDNA were detected in the liver tissues by PSAD + RCA + IS-PCR (c), whereas no positive signal was detected in the tissue sections that were subjected to IS-PCR (a) and PSAD + IS-PCR (b). (d) hematoxylin-eosin staining of FFPE liver biopsies of CHB patient. The arrow in the images shows HBVcccDNA positive signals in the hepatocyte nuclei. Original magnifications $\times 400$. 


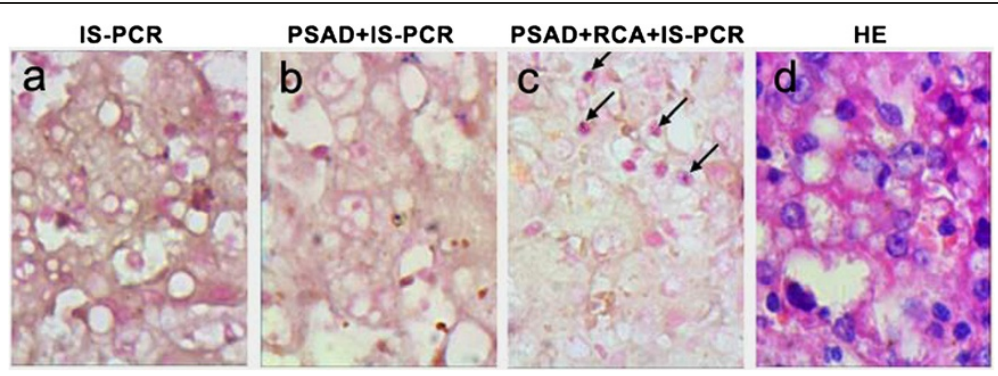

Figure 3 IS-PCR and immunohistochemical and HE staining for detecting HBV ccCDNA in FFPE liver biopsies of LC patient. HBV $c C C D N A$ were detected in the liver tissues by PSAD + RCA + IS-PCR (c), whereas no positive signal was detected in the tissue sections that were subjected to IS-PCR (a) and PSAD + IS-PCR (b). (d) hematoxylin-eosin staining of FFPE liver biopsies of LC patient. The arrow in the images shows HBVcccDNA positive signals in the hepatocyte nuclei. Original magnifications $\times 400$.

amplification cycles [30,31]. The key step in the IS-PCR is a controlled proteinase $\mathrm{K}$ pretreatment. Optimal proteinase treatment permeates sections sufficiently to permit entry of PCR reagents into cells without leakage of the PCR products or loss of tissue morphology. So, the concentration of proteinase $\mathrm{K}$ and the treatment time were adjusted to optimize permeability of membranes and the release of proteinnucleic acid cross-linking, while avoiding over digestivity. To minimize diffusion of the PCR products, we chose the optimal proteinase $\mathrm{K}$ concentration $(50 \mu \mathrm{g} / \mathrm{ml}$ for paraffin sections) for $10 \mathrm{~min}$, which produced a positive sharp in situ PCR signal. We also limited the number of PCR cycles, which was important for eliminating the background staining, as too many cycles resulted in high background staining and loss of tissue morphology. Finally, we fixed the liver tissue sections in $4 \%$ paraformaldehyde immediately after PCR amplification: this step is essential to avoid diffusion of PCR products into neighboring cells.

In this study, First of all, we used PSAD to digest linearization of the rcDNA. PSAD pretreatment proved to be necessary, without this step, there was an obvious increase of amplicons amount, which was reasonably coming from the nonspecific amplification. But the impact of integrated HBV DNA could not be excluded. To solve this problem, RCA in situ optimally performed at $30^{\circ} \mathrm{C}$ for
16 hrs. It can minimize the impact of integrated HBV DNA and obviously improve the specificity of HBV cccDNA assay. Finally, the slides were placed in an IS-PCR system and amplification reaction was performed as described in materials and methods. By means of this method, we obtained clear and reproducible patterns of distribution or localization of the HBV cccDNA in the liver tissue sections. Our results showed that HBV cccDNA were detected in a large number of hepatocytes in tissue sections from HBVinfected patients. Positive signals were observed in the nucleus despite of low copy number cccDNA ( 2 copies of target sequence per cell). These data indicate that the method is specific and sensitive for the detection of HBV cccDNA.

\section{Conclusions}

RCA combined with IS-PCR could sensitively and specifically detect HBV cccDNA in infected hepatocytes, and visualize the tissue staining patterns. Distribution and localization of HBV cccDNA in liver tissues could be made visible to the unaided eye under a light microscope, which can reflect the relationship between cccDNA expression level and liver tissue pathological characteristics so as to evaluate anti-HBV therapeutic efficacy. Our assay also may provide a powerful tool for discovering the existence of extrahepatic cccDNA.
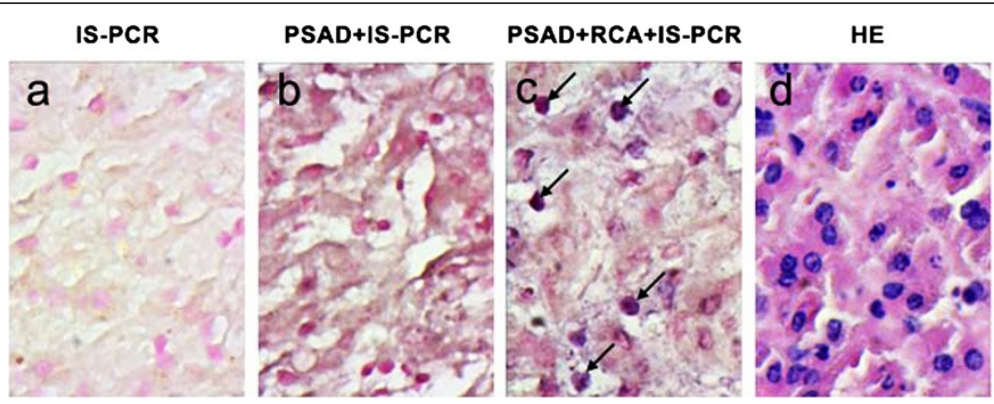

Figure 4 IS-PCR and immunohistochemical and HE staining for detecting HBV ccCDNA in FFPE liver biopsies of HCC patient.

HBV cccDNA were detected in the liver tissues by PSAD + RCA + IS-PCR (c), whereas no positive signal was detected in the tissue sections that were subjected to IS-PCR (a) and PSAD + IS-PCR (b). (d) hematoxylin-eosin staining of FFPE liver biopsies of HCC patient. The arrow in the images shows HBVcccDNA positive signals in the hepatocyte nuclei. Original magnifications $\times 400$. 


\section{Competing interests}

The authors declare that they have no competing interests.

\section{Authors' contributions}

YWZ, SYH designed and drafted the manuscript. YWZ, SYH, CX, YLZ YQZ, ZBL performed experiments. YWZ, SYH, CX, DPX, JMZ, XCZ, HFZ, JL analyzed data and discussed results. All authors read and approved the final manuscript.

\section{Acknowledgments}

This work was supported by the Capital Medical Developing Foundation of Beijing, China (No. 2009-3057) and the Military 12th Five-Year Plan for Science \& Technology Research of China (CWS11J161). The funders had no role in study design, data collection and analysis, and in the decision to publish, or in the preparation of the manuscript.

\section{Author details}

${ }^{1}$ Institute of Infectious Diseases, Beijing 302 Hospital, Beijing, China. ${ }^{2} \mathrm{He}$ Bei North University, Zhangjiakou, China.

Received: 6 January 2014 Accepted: 3 November 2014

Published online: 03 December 2014

\section{References}

1. Hosaka T, Suzuki F, Kobayashi M, Seko Y, Kawamura Y, Sezaki H, Akuta N, Suzuki Y, Saitoh S, Arase Y, Ikeda K, Kobayashi M, Kumada H: Long-term entecavir treatment reduces hepatocellular carcinoma incidence in patients with hepatitis B virus infection. Hepatology 2013, 58(1):98-107.

2. Zhong $Y, L V J, L i J$, Xing $X$, Zhu H: Prevalence, virology and antiviral drugs susceptibility of hepatitis $B$ virus rtN238H polymerase mutation from 1865 Chinese patients with chronic hepatitis B. Antiviral Res 2012, 93:185-190

3. Zhong YW, Li J, Song HB, Duan ZP, Dong Y: Virologic and clinical characteristics of HBV genotypes/subgenotypes in 487 Chinese pediatric patients with CHB. BMC Infect Dis 2011, 11:262.

4. Lin YJ, Lee $M H$, Yang $H I$, Jen CL, You SL: Predictability of liver-related Seromarkers for the risk of hepatocellular carcinoma in chronic hepatitis B patients. PLoS One 2013, 8(4):e61448. doi:10.1371.

5. Locarnini S, Hatzakis A, Heathcote J, Keeffe EB, Liang TJ: Management of antiviral resistance in patients with chronic hepatitis B. Antivir Ther 2004, 9:679-693.

6. Seeger C, Mason WS: Hepatitis B virus biology. Microbiol Mol Biol Rev 2000, 64:51-68.

7. Pawlotsky JM, Dusheiko G, Hatzakis A, Lau D, Lau G: Virologic monitoring of hepatitis $B$ virus therapy in clinical trials and practice: recommendations for a standardized. Gastroenterology 2008, 134:405-415.

8. Werle-Lapostolle B, Bowden S, Locarnini S, Wursthorn K, Petersen J: Persistence of cccDNA during the natural history of chronic hepatitis $B$ and decline during adefovir dipivoxil therapy. Gastroenterology 2004, 126:1750-1758.

9. Lenci I, Marcuccilli F, Tisone G, Di Paolo D, Tariciotti L: Total and covalently closed circular DNA detection in liver tissue of long-term survivors transplanted for HBV-related cirrhosis. Dig Liver Dis 2010, 42:578-584.

10. Lu L, Zhang HY, Yueng YH, Cheung KF, Luk JM: Intracellular levels of hepatitis $B$ virus DNA and pregenomic RNA in peripheral blood mononuclear cells of chronically infected patients. J Viral Hepat 2009, 16:104-112.

11. Wong DK, Yuen MF, Yuan H, Sum SS, Hui CK: Quantitation of covalently closed circular hepatitis B virus DNA in chronic hepatitis B patients. Hepatology 2004, 40:727-737.

12. Laras A, Koskinas J, Dimou E, Kostamena A, Hadziyannis SJ: Intrahepatic levels and replicative activity of covalently closed circular hepatitis B virus DNA in chronically infected patients. Hepatology 2006, 44:694-702.

13. Wursthorn K, Lutgehetmann M, Dandri M, Volz T, Buggisch P: Peginterferon alpha- $2 \mathrm{~b}$ plus adefovir induce strong cccDNA decline and $\mathrm{HBsAg}$ reduction in patients with chronic hepatitis B. Hepatology 2006, 44:675-684.

14. Zhong Y, Han J, Zou Z, Liu S, Tang B: Quantitation of HBV covalently closed circular DNA in micro formalin fixed paraffin-embedded liver tissue using rolling circle amplification in combination with real-time PCR. Clin Chim Acta 2012, 412:1905-1911.
15. Bowden S, Jackson K, Littlejohn M, Locarnini S: Quantification of HBV covalently closed circular DNA from liver tissue by real-time PCR. Methods Mol Med 2004, 95:41-50.

16. Singh M, Dicaire A, Wakil AE, Luscombe C, Sacks SL: Quantitation of hepatitis B virus (HBV) covalently closed circular DNA (cccDNA) in the liver of HBV-infected patients by LightcyclerTM real-time PCR. J Virol Methods 2004, 118:159-167.

17. Takkenberg RB, Zaaijer HL, Menting S, Weegink CJ, Terpstra V: Detection of hepatitis B virus covalently closed circular DNA in paraffin-embedded and cryo-preserved liver biopsies of chronic hepatitis B patients. Eur J Gastroenterol Hepatol 2010, 22:952-960.

18. Zhang DY, Brandwein M, Hsuih T, Li HB: Ramification amplification: a novel isothermal DNA amplification method. Mol Diagn 2001, 6:141-150.

19. Lasken RS, Egholm M: Whole genome amplification: abundant supplies of DNA from precious samples or clinical specimens. Trends Biotechnol 2003, 21:531-535.

20. Margeridon S, Carrouee-Durantel S, Chemin I, Barraud L, Zoulim F: Rolling circle amplification, a powerful tool for genetic and functional studies of complete hepatitis $B$ virus genomes from low-level infections and for directly probing covalently closed circular DNA. Antimicrob Agents Chemother 2008, 52:3068-3073.

21. Su HL, Liu YM, Ren XQ, Xu DP, Zhong YW: Comparative analysis of drug resistant mutations in the reverse transcriptase domain of hepatitis $B$ virus covalently closed circular DNA and the viral relax circle DNA. Chin J Hepatol 2010, 8:818-821.

22. Johne $R$, Muller $H$, Rector A, van Ranst M, Stevens $H$ : Rolling-circle amplification of viral DNA genomes using phi29 polymerase. Trends Microbiol 2009, 17:205-211.

23. Haase AT, Retzel EF, Staskus KA: Amplification and detection of lentiviral DNA inside cells. Proc Natl Acad Sci U S A 1990, 87:4971-4975.

24. Shieh B, Lee SE, Tsai YC, Su IJ, Li C: Detection of hepatitis B virus genome in hepatocellular carcinoma tissues with PCR-in situ hybridization. J Virol Methods 1990, 80:157-167.

25. Alzahrani AJ, Vallely PJ, McMahon RF: Development of a novel nested in situ PCR-ISH method for detection of hepatitis C virus RNA in liver tissue. J Virol Methods 2002, 99:53-61.

26. Nuriya $H$, Inoue $K$, Tanaka T, Hayashi $Y$, Hishima T: Detection of hepatitis B and $C$ viruses in almost all hepatocytes by modified PCR-based in situ hybridization. J Clin Microbiol 2010, 48:3843-3851.

27. Asan E: Progress in focus: recent advances in histochemistry and cell biology. Histochem Cell Biol 2002, 118:507-525.

28. Nuovo GJP: The utility of in situ-based methodologies including in situ polymerase chain reaction for the diagnosis and study of viral infections. Hum Pathol 2007, 38:1123-1136.

29. Teo IA, Shaunak S: Polymerase chain reaction in situ: an appraisal of an emerging technique. Histochem J 1995, 27:647-659.

30. Nuovo GJ, Gallery F, Hom R, MacConnell P, Bloch W: Importance of different variables for enhancing in situ detection of PCR-amplified DNA. PCR Methods Appl 1993, 2:305-312.

31. Zaki SR, Heneine W, Coffield LM, Greer PW, Sinha SD: In-situ polymerase chain reaction amplification: applications and current limitations. AIDS 1994, 8:1186-1187.

\section{doi:10.1186/s12879-014-0608-y}

Cite this article as: Zhong et al:: A novel method for detection of HBV cccDNA in hepatocytes using rolling circle amplification combined with in situ PCR. BMC Infectious Diseases 2014 14:608. 